\title{
BMJ Open Pharmacological and behavioural interventions to promote smoking cessation in adults with schizophrenia and bipolar disorders: a systematic review and meta-analysis of randomised trials
}

\author{
Robert Pearsall, ${ }^{1,2}$ Daniel J Smith (D) , ${ }^{2}$ John R Geddes ${ }^{3}$
}

To cite: Pearsall R, Smith DJ, Geddes JR. Pharmacological and behavioural interventions to promote smoking cessation in adults with schizophrenia and bipolar disorders: a systematic review and meta-analysis of randomised trials. BMJ Open 2019;9:e027389. doi:10.1136/ bmjopen-2018-027389

- Prepublication history and additional material for this paper are available online. To view these files, please visit the journal online (http://dx.doi. org/10.1136/bmjopen-2018027389).

Received 29 0ctober 2018 Revised 23 May 2019 Accepted 3 June 2019

Check for updates

(c) Author(s) (or their employer(s)) 2019. Re-use permitted under CC BY-NC. No commercial re-use. See rights and permissions. Published by BMJ.

${ }^{1}$ Department of Psychiatry, Monklands Hospital, Airdrie, UK ${ }^{2}$ Institute of Health and Wellbeing, University of Glasgow, Glasgow, UK ${ }^{3}$ Department of Psychiatry, University of Oxford, $0 x$ ford, UK

Correspondence to

Dr Robert Pearsall;

robert.pearsall@nhs.net

\section{ABSTRACT}

Objective Smoking in people with serious mental illness is a major public health problem and contributes to significant levels of morbidity and mortality. The aim of the review was to systematically examine the efficacy of methods used to aid smoking cessation in people with serious mental illness.

Method A systematic review and meta-analysis of randomised controlled trials to compare the effectiveness and safety of pharmacological and behavioural programmes for smoking cessation in people with serious mental illness. Electronic databases were searched for trials to July 2018. We used the Cochrane Collaboration's tool for assessing the risk of bias.

Results Twenty-eight randomised controlled trials were identified. Varenicline increased the likelihood of smoking cessation at both 3 months (risk ratio (RR) $3.56,95 \% \mathrm{Cl}$ 1.82 to $6.96, p=0.0002$ ) and at 6 months (RR 3.69, $95 \% \mathrm{Cl} 1.08$ to $12.60, p=0.04)$. Bupropion was effective at 3 months (RR $3.96,95 \% \mathrm{Cl} 1.86$ to $8.40, \mathrm{p}=0.0003$ ), especially at a dose of $300 \mathrm{mg} /$ day, but there was no evidence of effect at 6 months (RR $2.22,95 \% \mathrm{Cl} 0.52$ to $9.47, p=0.28)$. In one small study, nicotine therapy proved effective at increasing smoking cessation up to a period of 3 months. Bupropion used in conjunction with nicotine replacement therapy showed more effect than single use. Behavioural and bespoke interventions showed little overall benefit. Side effects were found to be low.

Conclusion The new information of this review was the effectiveness of varenicline for smoking cessation at both 3 and 6 months and the lack of evidence to support the use of both bupropion and nicotine products for sustained abstinence longer than 3 months. Overall, the review found relatively few studies in this population.

\section{INTRODUCTION}

Smoking in people with serious mental illness continues to be a major public health problem with levels of smoking remaining as high as $70 \%,{ }^{1-3}$ compared with about $20 \%$ in the general population. ${ }^{4}$ Smoking
Strengths and limitations of this study

- This study systematically reviewed all pharmacological and behavioural interventions to promote smoking cessation in people with serious mental illness.

- We used the Grading of Recommendations Assessment, Development and Evaluation approach to evaluate the strength and quality of the evidence.

- We reviewed and identified evidence that would be valuable and relevant to clinical practice.

- Research in this field was limited by a small number and low quality of randomised controlled trials.

- We recommended that studies with larger sample sizes are needed particularly to compare the relative effects of one smoking treatment versus another.

contributes to the high levels of morbidity and mortality in this population ${ }^{5}$ with mortality rates continuing to remain around twice those found in the general population, with high levels of cardiovascular and respiratory disease. ${ }^{167}$ Individuals with serious mental illness tend to have smoked for longer periods compared with other groups and are commonly classed as heavy smokers, smoking $>25$ cigarettes per day. ${ }^{8}$ They often start before the onset of their illness, are younger than non-smokers and most of them are male. ${ }^{9}$ Generally, they prefer cigarettes high in nicotine and more frequently smoke cigarettes down to the very end. ${ }^{10}$ Increased nicotine intake per cigarette is associated with more intense cigarette puffing contributing to the higher serum nicotine levels, approximately 1.3 times those in non-mentally ill controls. ${ }^{112}$ The effect of this greater uptake of nicotine may lead to higher than expected levels of nicotine dependence and 


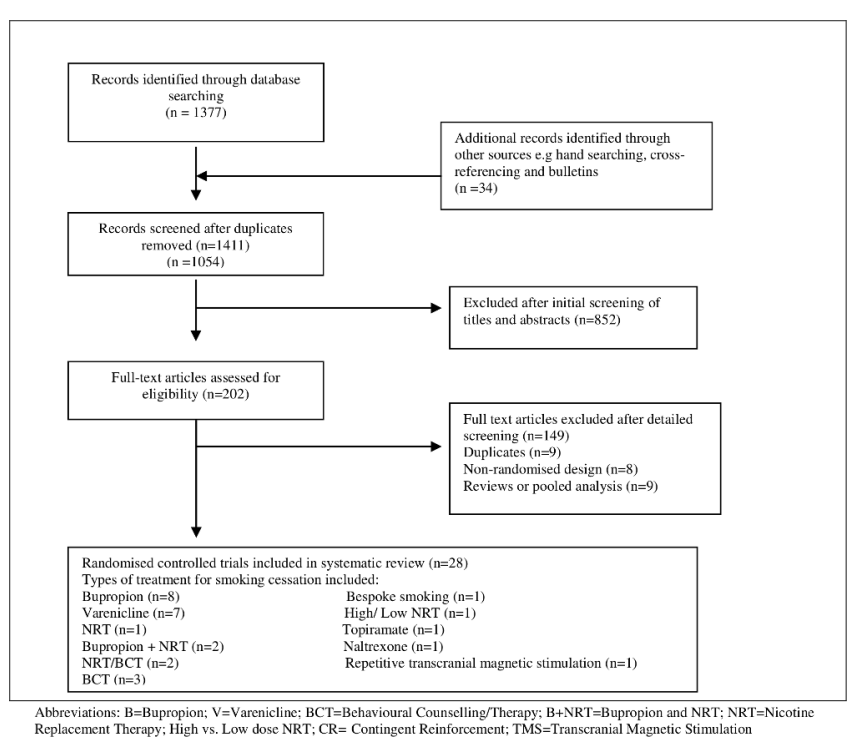

Figure 1 Flow chart of the results of the systematic search. NRT, nicotine replacement therapy.

withdrawal symptoms, even with moderate amounts of smoking. ${ }^{11}$

There is therefore an urgent need to develop and evaluate smoking cessation interventions that work in clinical settings for people with severe mental illness who are about as likely as the general population to want to quit smoking. ${ }^{13}$ However, so far the primary focus of existing smoking cessation programmes in this population has been based on the use of nicotine replacement products. There is a reluctance among some clinicians to consider new treatments that may be more effective. This may be due to lack of clarity on the effectiveness of these products or concern about side effects. ${ }^{14}$ Early reports using medication such as varenicline had raised concerns as to its effect on the mental health of individuals. ${ }^{15}$

The aim of this new review was to compare the effectiveness and safety of existing pharmacological and behavioural programmes for smoking cessation in people with serious mental illness. Clinicians need clear information to be able to compare the relative benefits and potential side effects of these treatments for their patients.

\section{METHODS}

Criteria for considering studies for this review.

\section{Types of studies}

All randomised controlled trials.

\section{Types of participants}

Adults with schizophrenia or other types of schizophrenia-like psychosis, schizoaffective disorders and bipolar affective disorder, irrespective of the diagnostic criteria used, age, ethnicity and sex.

\section{Types of interventions}

We only included interventions where the primary aim of the study was to achieve smoking cessation.

\section{Types of outcome measures}

We used the strictest definition of abstinence, that is, preferring sustained over point prevalence abstinence and using biochemically validated rates where available. However, if this was not available the best alternative would be used. When both outcomes were available, we considered sustained abstinence to be a superior clinical marker of abstinence. Secondary outcome measures were changes in safety (adverse effects), mental state, general functioning and cognitive functioning.

\section{Search methods and study selection}

We searched the following electronic databases: Ovid MEDLINE, Embase, CINAHL, PsycINFO, Biological Abstracts on Ovid and The Cochrane Library (start January 2017, last search July 2018). The systematic search (online supplementary appendix A) included hand searching of journals, books, cross-referencing and bulletins (eg, brief reports/brief statement of facts). The search filter, the Cochrane Highly Sensitive Search Strategy, was used to assist in the identification of randomised trials in MEDLINE. ${ }^{16}$ No articles were excluded on the basis of language during the search.

The abstracts of studies were examined by RP. Full text of the studies that potentially met the eligibility criteria was obtained. Selection of studies was conducted by RP and any discrepancies or difficulties were discussed with co-investigators (JG and DJS). Articles were checked for duplication of the same data. Smoking cessation was measured at 3,6 and 12 months if possible, or the closest available data to that time point. Side effects were measured at the available data end points at 3,6 and 12 months, if possible.

\section{Data extraction and analysis}

Data were extracted by one author (RP) and checked for accuracy by the second (DJS). Data were extracted onto prepared forms to include: participants and setting, location, description of the intervention, study size, methodological issues, risk of bias, results and general comments. All analyses were conducted using RevMan Manager V.5.3. We performed a Preferred Reporting Items for Systematic Reviews and Meta-Analyses evaluation of our meta-analysis using a standard checklist of 27 items that ensure the quality of a systematic review or meta-analysis. ${ }^{17}$

Data from intention to treat analyses were used when available or endpoint data for participants who completed the programme. For dichotomous outcomes, the fixed effects risk ratio (RR) and its 95\% CI were calculated using the Mantel-Haenszel method. ${ }^{18}$ If heterogeneity was found, a random effects model was used. For continuous data, the standardised mean difference (SMD) with 95\% confidence intervals was calculated as the difference in means between groups divided by the pooled SD. If no SD were found they were calculated from standard errors, confidence intervals, or t values. ${ }^{19}$ Authors were contacted for missing data if analyses could not be completed. Statistical heterogeneity was investigated using two methods: 


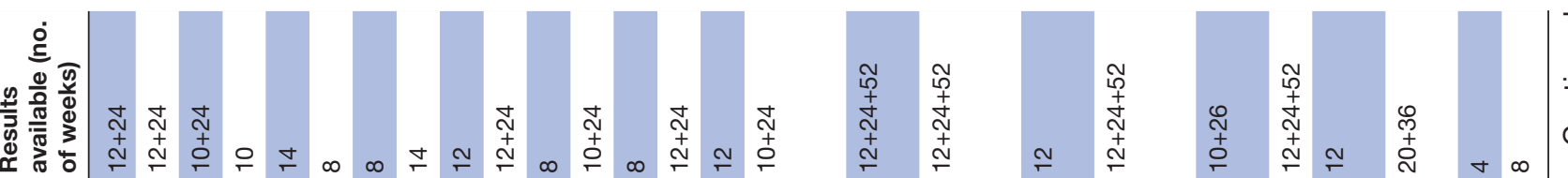

สำ

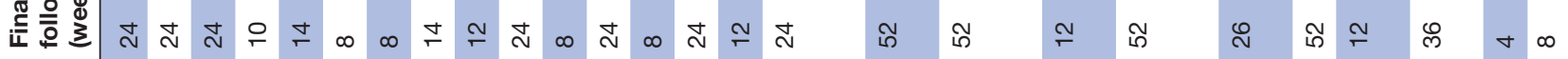
도

을

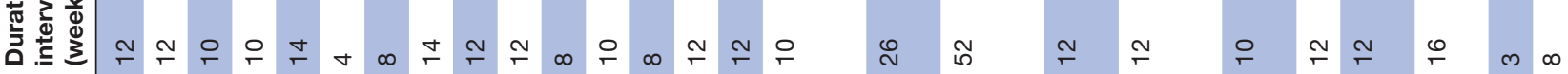

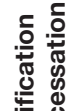

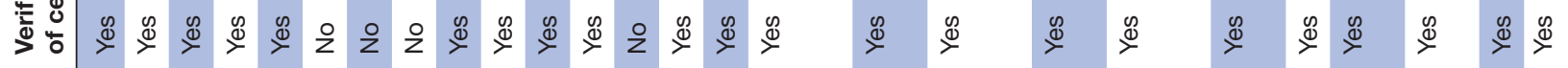

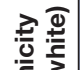

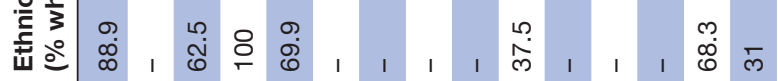

ஸ்

$\stackrel{0}{\circ}$

ஸे

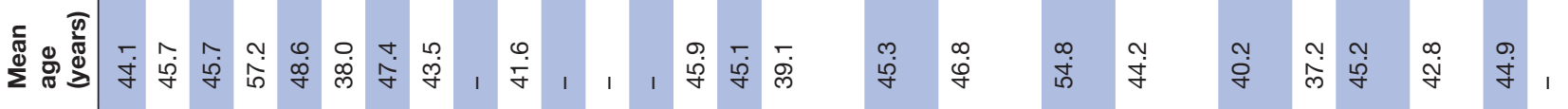

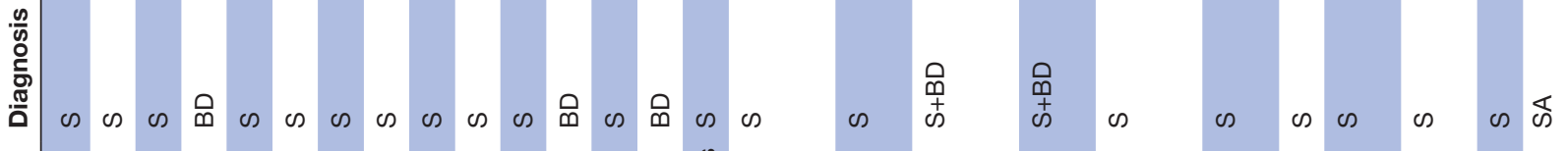

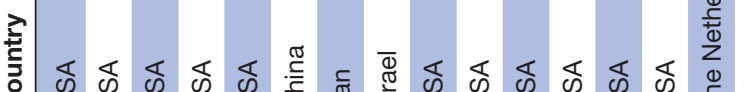

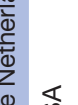

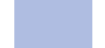

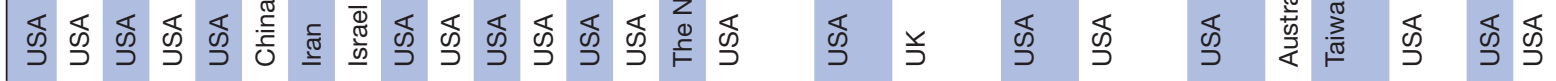

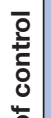

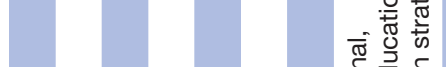

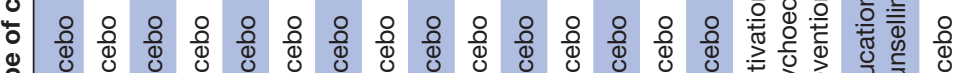

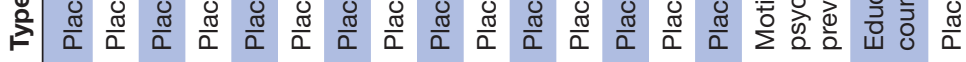

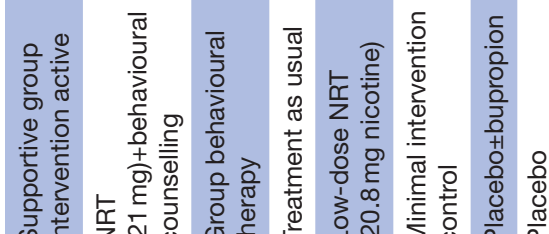

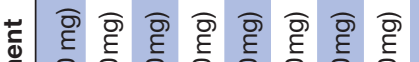

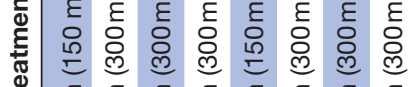

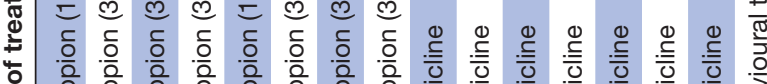

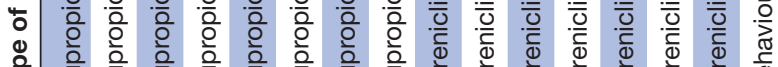

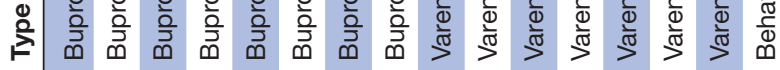

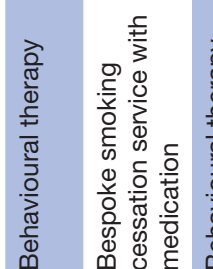

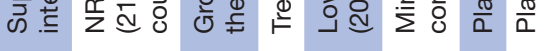

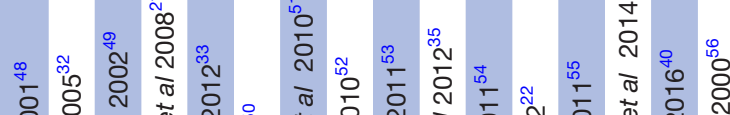

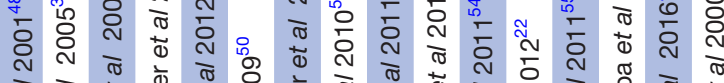

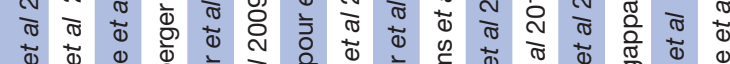

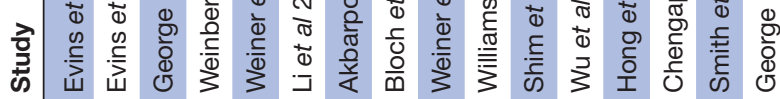

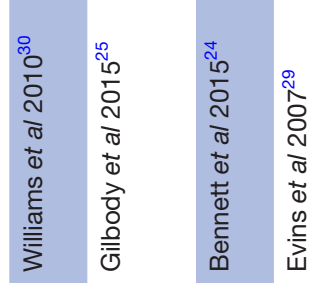

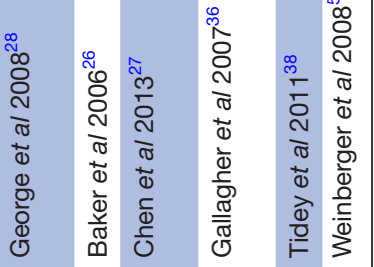


visual inspection of the forest plots and the $\mathrm{I}^{2}$ test. The degree of heterogeneity was categorised as follows: $0 \%$ to $40 \%$ low level of heterogeneity; $30 \%$ to $60 \%$ moderate heterogeneity; $50 \%$ to $90 \%$ substantial heterogeneity; $75 \%$ to $100 \%$ : considerable heterogeneity. ${ }^{19}$

Sensitivity analyses were conducted to determine the effect of dosage of medication used, and whether chemical confirmation of smoking cessation affected treatment outcomes. It was planned to use funnel plots to assess publication bias graphically and Begg and Egger tests to assess the risk of bias statistically. ${ }^{19}{ }^{20}$ We performed sensitivity analyses to explore the influence of each risk of bias domain on pooled treatment effects where the risk was high.

The safety outcomes extracted from included trials were the number of patients reporting any adverse event, the number of patients reporting any serious adverse event, and number of patients withdrawn from the study because of adverse events. We contacted authors to provide further information when there were insufficient data reported in the paper. Data were pooled for the identified adverse events.

\section{Quality assessment}

We used the Cochrane Collaboration's tool for assessing the risk of bias. ${ }^{19}$ The following recommended domains were considered: sequence generation, allocation concealment, blinding, incomplete outcome data, selective outcome reporting and other sources of bias. Each item was rated according to the level of bias and categorised into either low, high or unclear. The category unclear indicated unclear or unknown risk of bias. ${ }^{19}$ RevMan V.5.3.5 was used to generate figures and summaries.

The quality of evidence was rated for each pooled analysis with the Grading of Recommendations Assessment, Development and Evaluation (GRADE) system. ${ }^{19}$ Outcomes of interest were ranked according to their relevance for clinical decision.

\section{Patient and public involvement statement}

No patients or public representatives were involved in the completion of this review.

\section{RESULTS}

The electronic search identified 1377 potentially eligible reports. Eight hundred and fifty-two were excluded on the basis of the title or abstract alone. We retrieved the full text of 202 articles and excluded a further 174 studies (figure 1, online supplementary appendix B). Additional papers were found from searching, cross-referencing and bulletins.

All included studies had been published between 2000 and 2016. A total of 28 studies were identified. The studies varied in their setting, size, age and type of intervention (table 1). Only five studies examined individuals with bipolar affective disorder. ${ }^{21-25}$ Of these, two studies were of varenicline, one of bupropion and two 
Table 2 Meta-analysis comparison: risk ratio of smoking cessation at 3 months

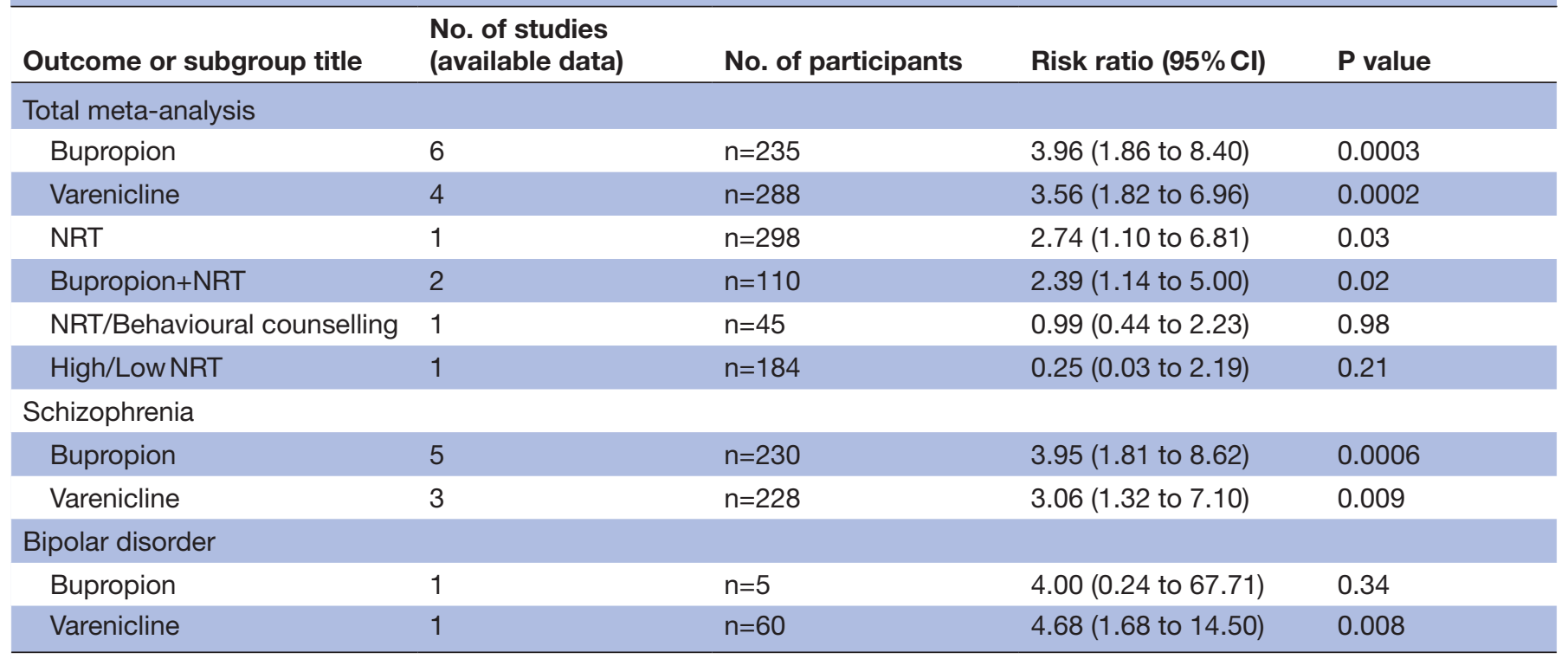

NRT, nicotine replacement therapy.

using behavioural techniques in both schizophrenia and bipolar disorder. We found eight studies comparing bupropion versus placebo (table 1).

Six studies used $300 \mathrm{mg}$ of bupropion per day and two used bupropion $150 \mathrm{mg} /$ day. Seven studies examined the effect of varenicline versus placebo, and one study nicotine replacement therapy (NRT) versus placebo (table 1).

\section{Outcomes}

The main outcome measure was smoking abstinence at 3 and 6 months. Twelve-month follow-up was found in four studies (table 1). Five studies did not confirm smoking abstinence using chemical markers (table 1).

\section{Meta-analyses}

Bupropion

Six out of eight studies provided data to combine the effects of bupropion versus placebo (table 2). The pooled risk ratio (RR) of bupropion (150 and $300 \mathrm{mg} /$ day) at 3 months for smoking abstinence favoured bupropion against placebo $(n=6, n=235, R R 3.96,95 \%$ CI
1.86 to $8.40, \mathrm{p}=0.0003$; heterogeneity: $\mathrm{X}^{2}=1.64, \mathrm{df}=5$, $\mathrm{p}=0.90 ; \mathrm{I}^{2}=0 \%$ ) (figure 2 ).

Pooled results at 6 months of bupropion versus placebo showed no effect $(n=3, n=104$, RR 2.22, 95\% CI 0.52 to $9.47, \mathrm{p}=0.28$; heterogeneity: $\chi^{2}=0.34, \mathrm{df}=2, \mathrm{p}=0.85$; $\mathrm{I}^{2}=0 \%$ ) (figure 3 ). The pooled RR showed a greater likelihood of smoking cessation using a dose of $300 \mathrm{mg} /$ day of bupropion at 3 months (dose $150 \mathrm{mg}$ : n=2, n=65, RR 2.01, 95\% CI 0.49 to $8.28, \mathrm{p}=0.33$; dose $300 \mathrm{mg}: \mathrm{n}=4, \mathrm{n}=170$, RR $4.99,95 \%$ CI 2.01 to $12.39, \mathrm{p}=0.0005)$. No effect was found using doses of 150 or $300 \mathrm{mg} /$ day at 6 months (dose 150 mg: $n=1, n=19$, RR 2.73, $95 \%$ CI 0.12 to $59.57, p=0.52$; dose $300 \mathrm{mg}: \mathrm{n}=2, \mathrm{n}=85$, RR 2.09 , $95 \%$ CI 0.40 to 10.80 , $\mathrm{p}=0.38)$.

Bupropion was effective for smoking cessation in individuals with a diagnosis of schizophrenia at 3 months $(\mathrm{n}=5, \mathrm{n}=230$, RR $3.95,95 \%$ CI 1.81 to $8.62, \mathrm{p}=0.0006)$. No effect was found in bipolar disorders in one small study $(\mathrm{n}=1, \mathrm{n}=5, \mathrm{RR} 4.00,95 \%$ CI 0.24 to $67.71, \mathrm{p}=0.34)$ (table 2).

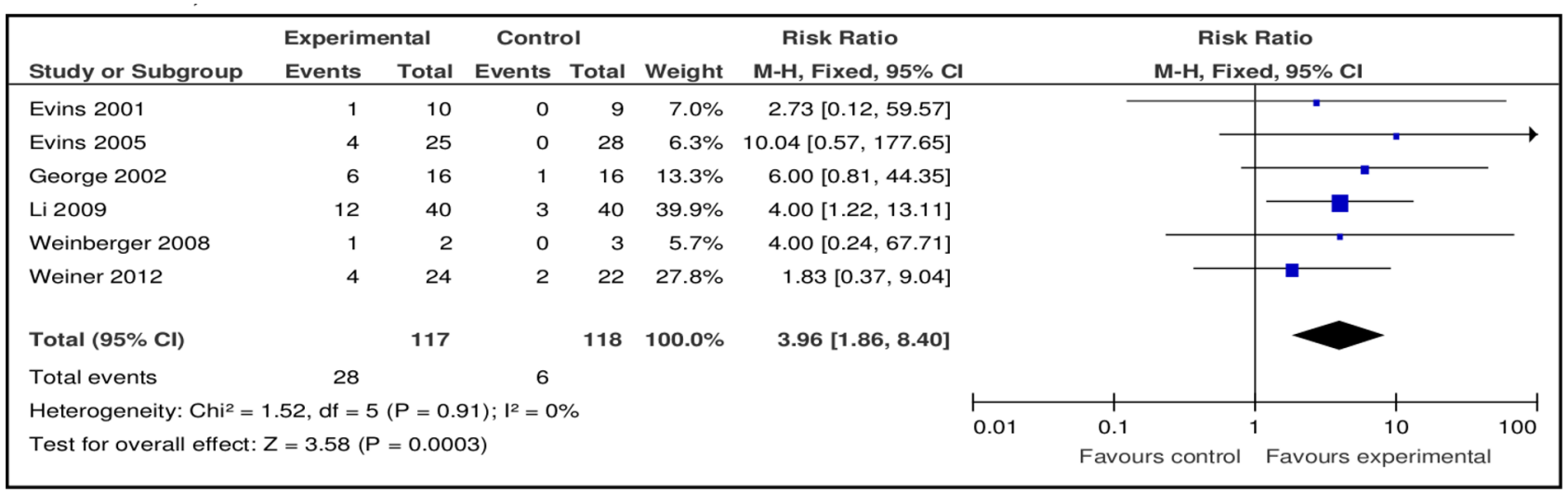

Figure 2 Pooled effect of bupropion vs placebo for smoking cessation at 3 months. 


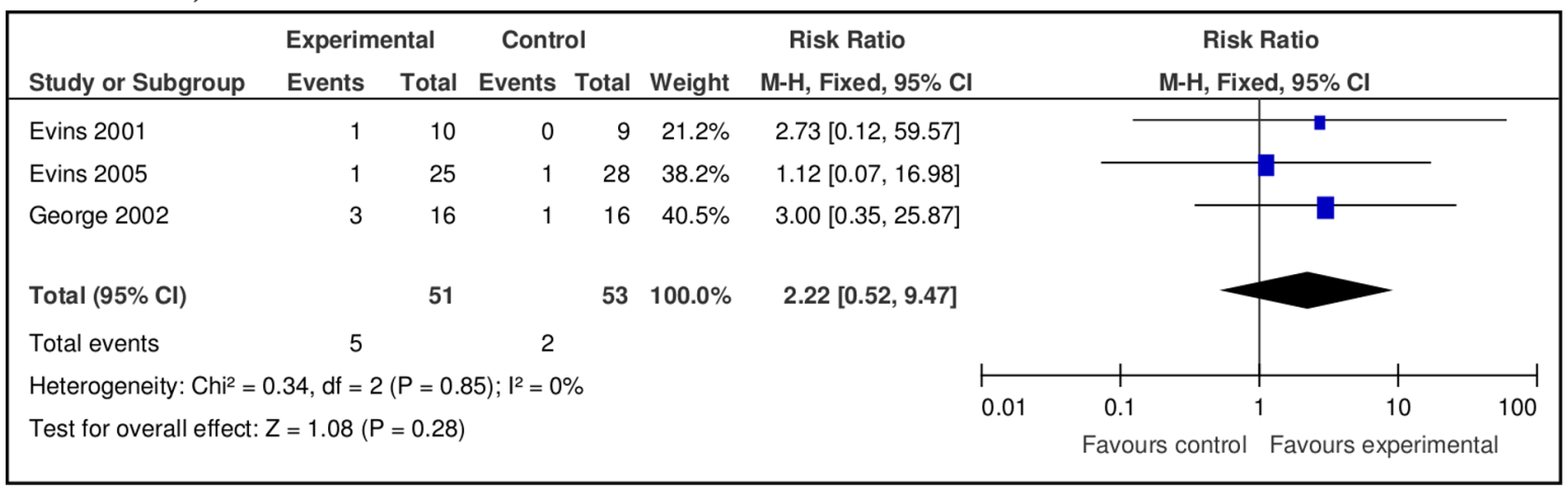

Figure 3 Pooled effect of bupropion vs placebo for smoking cessation at 6 months.

\section{Varenicline}

Four out of seven studies provided data comparing the effect of varenicline with placebo. The pooled RR at 3 months for smoking abstinence favoured varencline $(\mathrm{n}=4, \mathrm{n}=288$, RR $3.56,95 \%$ CI 1.82 to $6.96, \mathrm{p}=0.0002$; heterogeneity: $\mathrm{X}^{2}=1.99, \mathrm{df}=3, \mathrm{p}=0.57 ; \mathrm{I}^{2}=0 \%$ ) (figure 4 ). Pooled analysis at 6 months also favoured varenicline $(\mathrm{n}=2$, $\mathrm{n}=188$, RR 3.69, 95\% CI 1.08 to $12.60, \mathrm{p}=0.04$; heterogeneity: $\chi^{2}=0.22, \mathrm{df}=1, \mathrm{p}=0.64 ; \mathrm{I}^{2}=0 \%$ ) (figure 5 ). Varenicline was effective for smoking cessation at 3 months in both schizophrenia and bipolar disorder (table 2) (RR 3.06 vs 4.68). However at 6 months no effect was found in either disorder.

\section{Nicotine replacement therapy}

Baker $e t a l^{26}$ compared NRT versus placebo at 3,6 and 12 months (figure 6). The RR favoured NRT at 3 months $(\mathrm{n}=1, \mathrm{n}=298$, RR $2.74,95 \%$ CI 1.10 to $6.81, \mathrm{p}=0.03)$, but not at 6 months $(\mathrm{n}=298$, RR 2.74, 95\% CI 0.74 to 10.12 , $\mathrm{p}=0.13)$ or 12 months $(\mathrm{n}=298, \mathrm{RR} \quad 5.14,95 \% \mathrm{CI}$ 0.61 to $43.44, \mathrm{p}=0.13)$. Chen $e t a l^{27}$ compared high-dose versus low-dose NRT, but found no difference in effect at 3 months ( $\mathrm{n}=184$, RR $0.25,95 \%$ CI 0.03 to $2.19, \mathrm{p}=0.21$ ).

\section{Combinations of treatment included in the meta-analyses}

Several studies used combinations of treatments for smoking cessation. Data from two studies were combined comparing the effects of bupropion and NRT therapy versus placebo, at 3 and 6 months. ${ }^{28}{ }^{29}$ The pooled RR favoured the combination of treatments at 3 months $(\mathrm{n}=2, \mathrm{n}=110, \mathrm{RR} 2.88,95 \%$ CI 1.23 to $6.73, \mathrm{p}=0.01$; heterogeneity: $\left.\mathrm{X}^{2}=1.72, \mathrm{df}=1, \mathrm{p}=0.19 ; \mathrm{I}^{2}=42 \%\right)$ and at 6 months $(\mathrm{n}=2, \mathrm{n}=110$, RR $3.86,95 \%$ CI 1.01 to 14.80 , $\mathrm{p}=0.05$; heterogeneity: $\left.\mathrm{X}^{2}=0.56, \mathrm{df}=1, \mathrm{p}=0.46, \mathrm{I}^{2}=0 \%\right)$. Of these studies, Evins $e t a l^{2}$ found no effect (n=51, RR 2.60, $95 \%$ CI 0.55 to $12.19, \mathrm{p}=0.23)$.

However, data from all studies of bupropion using bupropion treatment alone and two studies combining bupropion and NRT versus placebo were favourable at 3 months $(n=8, n=345$, RR $3.48,95 \%$ CI 1.98 to 6.11 , $\mathrm{p}=0.0001$; heterogeneity: $\mathrm{X}^{2}=3.77, \mathrm{df}=7, \mathrm{p}=0.81, \mathrm{I}^{2}=0 \%$ ) and 6 months ( $\mathrm{n}=5, \mathrm{n}=214$, RR 3.04, 95\% CI 1.14 to 8.09 , $\mathrm{p}=0.03$; heterogeneity: $\mathrm{X}^{2}=1.08, \mathrm{df}=4, \mathrm{p}=0.90, \mathrm{I}^{2}=0 \%$ ) (figure 7).

\section{Behavioural and bespoke programmes}

No meta-analysis was used due to the heterogeneity of both intervention and comparison groups (online supplementary appendix C, Table 1). Two studies compared the effect of NRT with different types of behavioural counselling. ${ }^{30}{ }^{31}$ George et $a l^{31}$ found no effect at 3 months $(\mathrm{n}=45$, RR $1.01,95 \%$ CI 0.45 to $2.28, \mathrm{p}=0.98)$ or 6 months $(\mathrm{n}=45$, RR $0.61,95 \%$ CI 0.14 to $2.67, \mathrm{p}=0.51)$. Williams $e t$ $a P^{30}$ compared two behavioural counselling approaches, high-intensity (TANS: Treatment of Addiction to Nicotine in Schizophrenia) versus a low-intensity behavioural counselling programme (MM: Medication Management).

\begin{tabular}{|c|c|c|c|c|c|c|c|c|}
\hline \multirow{3}{*}{$\begin{array}{l}\text { Study or Subgroup } \\
\text { Chengappa } 2014\end{array}$} & \multicolumn{2}{|c|}{ Experimental } & \multicolumn{2}{|c|}{ Control } & \multirow[b]{2}{*}{ Weight } & \multirow{2}{*}{$\begin{array}{c}\text { Risk Ratio } \\
\text { M-H, Fixed, 95\% CI }\end{array}$} & \multirow{2}{*}{\multicolumn{2}{|c|}{$\begin{array}{c}\text { Risk Ratio } \\
\text { M-H, Fixed, 95\% Cl }\end{array}$}} \\
\hline & Events & Total & Events & Total & & & & \\
\hline & 15 & 31 & 3 & 29 & $30.5 \%$ & $4.68[1.51,14.50]$ & & $\longrightarrow$ \\
\hline Smith 2016 & 7 & 45 & 4 & 46 & $38.9 \%$ & $1.79[0.56,5.69]$ & & \\
\hline Weiner 2011 & 3 & 4 & 0 & 5 & $4.5 \%$ & $8.40[0.56,126.90]$ & & \\
\hline Williams 2012 & 16 & 85 & 2 & 43 & $26.1 \%$ & $4.05[0.97,16.80]$ & & \\
\hline Total $(95 \% \mathrm{Cl})$ & & 165 & & 123 & $100.0 \%$ & $3.56[1.82,6.96]$ & & \\
\hline Total events & 41 & & 9 & & & & & \\
\hline \multicolumn{7}{|c|}{ Heterogeneity: $\mathrm{Chi}^{2}=1.99, \mathrm{df}=3(\mathrm{P}=0.57) ; \mathrm{I}^{2}=0 \%$} & $\begin{array}{lll}0.01 & 0.1 & 1\end{array}$ & 100 \\
\hline \multicolumn{7}{|c|}{ Test for overall effect: $Z=3.70(P=0.0002)$} & Favours control & Favours experimenta \\
\hline
\end{tabular}

Figure 4 Pooled effect of varenicline vs placebo for smoking cessation at 3 months. 


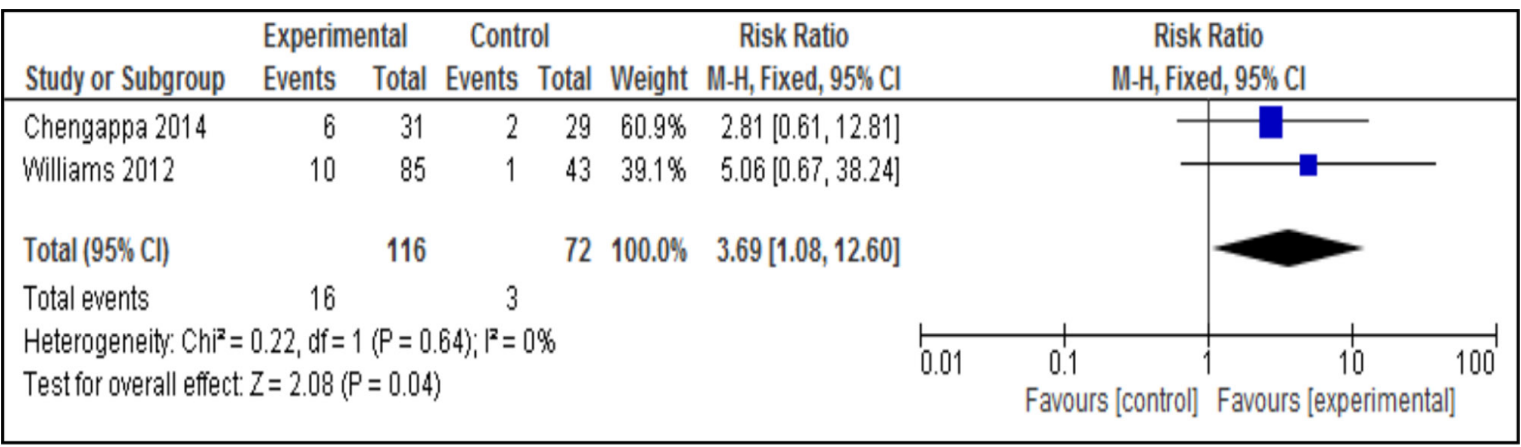

Figure 5 Pooled effect of varenicline vs placebo for smoking cessation at 6 months.

No difference in levels of smoking cessation was found in both groups at 3 months (15.6\% TANS vs. $26.2 \% \mathrm{MM}$, $\mathrm{p}=0.221$ ).

Bennett $e t a l^{24}$ compared a multifaceted behavioural group intervention versus a supportive group intervention and found no difference in effect at 3 months $(\mathrm{n}=95$, RR $1.13,95 \%$ CI 0.37 to $3.44, \mathrm{p}=0.83$ ). Some individuals used medication to support smoking cessation such as bupropion or NRT.

Gilbody et $a l^{25}$ offered a bespoke smoking cessation (BSC) programme (SCIMITAR) to individuals with serious mental illness compared with usual care. Pharmacotherapies were prescribed by the individual's general practitioner (GP) to aid smoking cessation (BSC group: nicotine $=77$, bupropion $=0$, varenicline $=0$, e-cigarette $=3$, either separately or in combination, as decided by the GP). During the trial period $48 \%$ of individuals in the intervention group received pharmacotherapies compared with $19 \%$ of the placebo group. The odds of quitting at 12 months was higher in the BSC intervention (36\% vs $23 \%)$ but did not reach statistical significance (OR 2.94, 95\% CI 0.8 to $10.5, \mathrm{p}=0.1$ ).

\section{Sensitivity analyses}

Sensitivity analyses found that bupropion at a dose of $300 \mathrm{mg}$ /day increased the likelihood of smoking cessation at 3 months (dose $150 \mathrm{mg}: \mathrm{n}=2, \mathrm{n}=65$, RR 2.01, 95\% CI 0.49 to $8.28, \mathrm{p}=0.33$; dose $300 \mathrm{mg}$ : $\mathrm{n}=4, \mathrm{n}=170$, RR 4.99, $95 \%$ CI 2.01 to $12.39, p=0.0005$ ). Studies that did not use chemical markers to confirm smoking cessation did not substantially affect the likelihood of cessation with bupropion ( $\mathrm{n}=5, \mathrm{n}=155$, RR 3.93 , 95\% CI 1.48 to 10.40 , $\mathrm{p}=0.006$ ). Chemical verification of smoking cessation was used in all studies of varenicline and NRT included in the meta-analysis in this review.

\section{Clinical effectiveness and numbers needed to treat}

The number needed to treat (NNT) for the cessation of smoking using varenicline at 3 months was six patients (risk difference (RD) $0.19,95 \%$ CI 0.11 to 0.27 ) (table 3 ), and 10 patients at 6 months (RD $0.1,95 \%$ CI 0.03 to 0.18 ). Varenicline resulted in $24.8 \%$ of the patients in the intervention group vs $7.3 \%$ patients in the placebo group being abstinent from smoking at 3 months (at 6 months this was $13.8 \%$ vs $4.2 \%$, respectively).

The NNT for the cessation of smoking using bupropion at 3 months was six patients (RD $0.19,95 \%$ CI 0.10 to 0.28 ) (table 3 ). NRT was the least effective, requiring 15 patients to receive treatment at 3 months (RD 0.07, $95 \%$ CI 0.01 to 0.13 ). Combinations proved to be the least effective of treatments to aid cessation of smoking (table 3).

\section{Side effects}

Side effects from medication were reviewed systematically to allow pooling of data where possible (table 4). Pooled analysis found that bupropion did not affect positive and negative symptoms or depressive and anxiety symptoms. Serious adverse events in individual patients were noted with bupropion. Evins $e t a l^{32}$ found that one participant, who was randomised to bupropion, experienced hives, urticaria and wheezing in the first week on

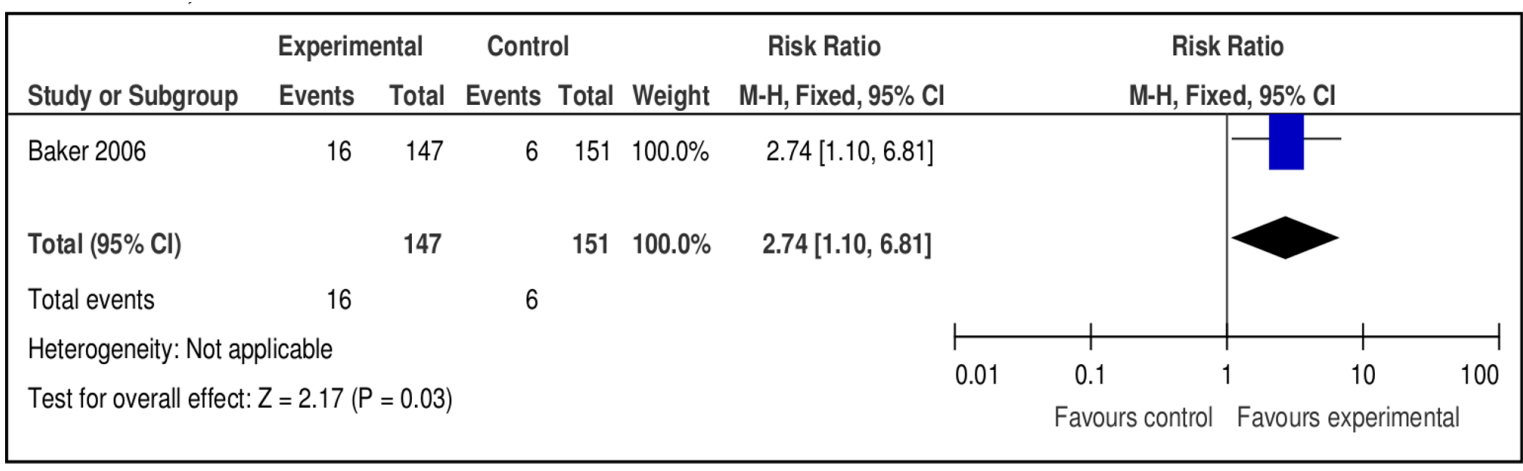

Figure 6 Pooled effect of nicotine replacement therapy vs placebo for smoking cessation at 3 months. 


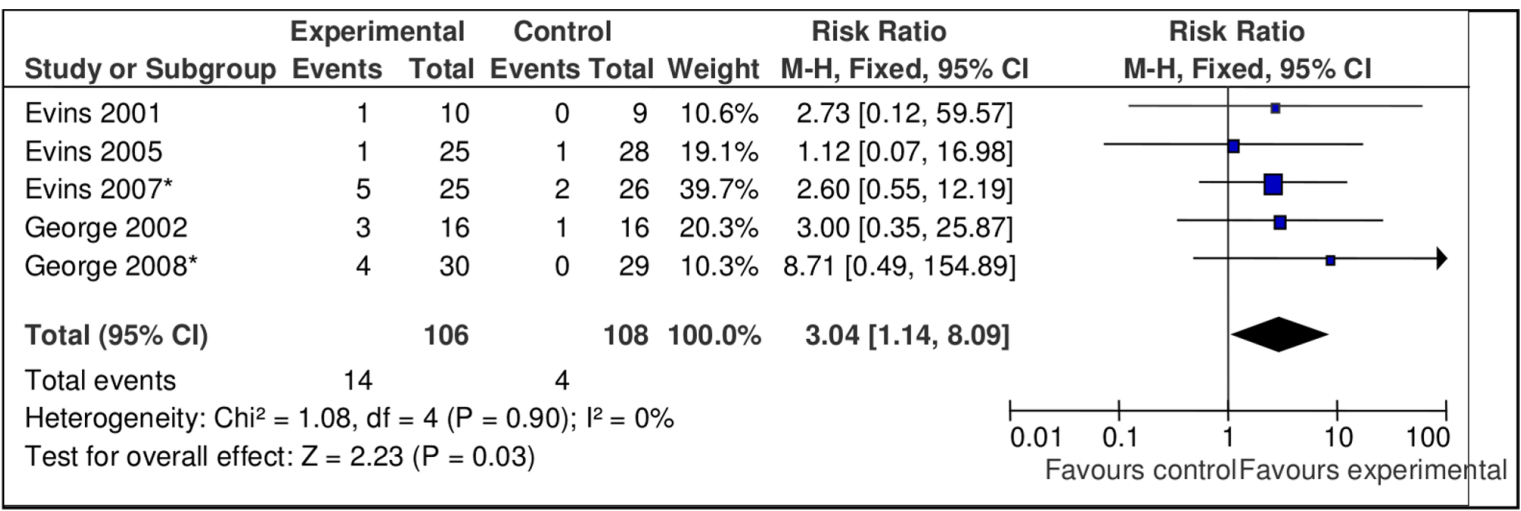

Figure 7 Pooled effect of bupropion only and combined bupropion/nicotine replacement therapy studies vs placebo for smoking cessation at 6 months.

study medication, consistent with an allergic reaction to bupropion. Weiner $e t a l^{33}$ found that one participant developed a rash that resolved after medication discontinued. Another patient suffered a seizure and was found to be hyponatraemic.

Pooled analysis showed a low level of side effects with varenicline (table 4 ). The main finding was that varenicline led to problems with nausea and vomiting, but had no other effects on depressive symptoms, anxiety symptoms or suicidal ideation. Serious adverse events were noted with varenicline in individual patients. Williams $e t$ $a l^{34}$ found that five patients in the treatment group and three patients in the placebo group experienced suicidal thoughts. However, the authors found no clear pattern between suicidal thoughts and medication assignment. One patient with depression and suicidal thoughts took an overdose of medication, while another participant took an overdose and had a seizure. Wu et $a l^{22}$ found that one patient experienced suicidal ideation but this was reported to be associated with additional situational stressors rather than a medication effect.

No notable side effects were described for programmes using NRT (table 4).

\section{Quality assessment}

We found a total of 28 studies which varied in their methodological quality, including the method of sequence generation during randomisation, sequence allocation concealment, blinding of participants, outcome assessment and incomplete analysis of outcome data (online supplementary appendix D, Table 1). Ten studies $^{23}$ 26-28 33 35-39 described using intention-to-treat analysis for data analysis. Participants failing to complete these studies were included as non-abstinent smokers in their analysis. Only three studies ${ }^{23} 2935$ described a sample size calculation. The interpretation of funnel plots (figure 8) was limited due to the small number of pooled results in this analysis, and similarly Egger tests were not preformed due to the low number of available studies.

We used the Cochrane Collaboration's tool $^{19}$ for assessing the risk of bias (figure 9). This showed that most studies described used inadequate methods of sequence generation during randomisation, blinding of participants, analysis of outcome data, poorer methods of allocation concealment and blinding of outcome assessment. We found that Smith $e t a l^{40}$ showed the lowest risk of bias in all domains.

The quality of evidence was rated for each pooled analysis with the GRADE assessment of study quality. The GRADE clinical evidence profile graded the studies of bupropion (at 3 or 6 months) and varenicline as being of very low quality (online supplementary file 4, Tables 2-3).

\section{DISCUSSION}

In this review, we compare up-to-date findings of programmes used to aid the cessation of smoking for

Table 3 Risk difference (RD) and number needed to treat (NNT) of smoking cessation at 3 months

\begin{tabular}{llllll}
\hline $\begin{array}{l}\text { Outcome or } \\
\text { subgroup title }\end{array}$ & No. of studies & No. of participants RD & NNT & P value \\
\hline $\begin{array}{l}\text { Bupropion } \\
\text { Varenicline }\end{array}$ & 6 & 235 & $0.19(0.10$ to 0.28$)$ & 6 & $<0.0001$ \\
NRT & 4 & 288 & $0.19(0.11$ to 0.27$)$ & 6 & $<0.00001$ \\
Bupropion+NRT & 2 & 298 & $0.07(0.01$ to 0.13$)$ & 15 & 0.02 \\
$\begin{array}{l}\text { NRT/Behavioural } \\
\text { counselling }\end{array}$ & 1 & 110 & $0.20(0.05$ to 0.36$)$ & 5 & 0.006 \\
High/Low NRT & 1 & 45 & $0.00(-0.28$ to 0.29$)$ & - & 0.98 \\
\hline
\end{tabular}


Table 4 Smoking cessation side effects of treatment

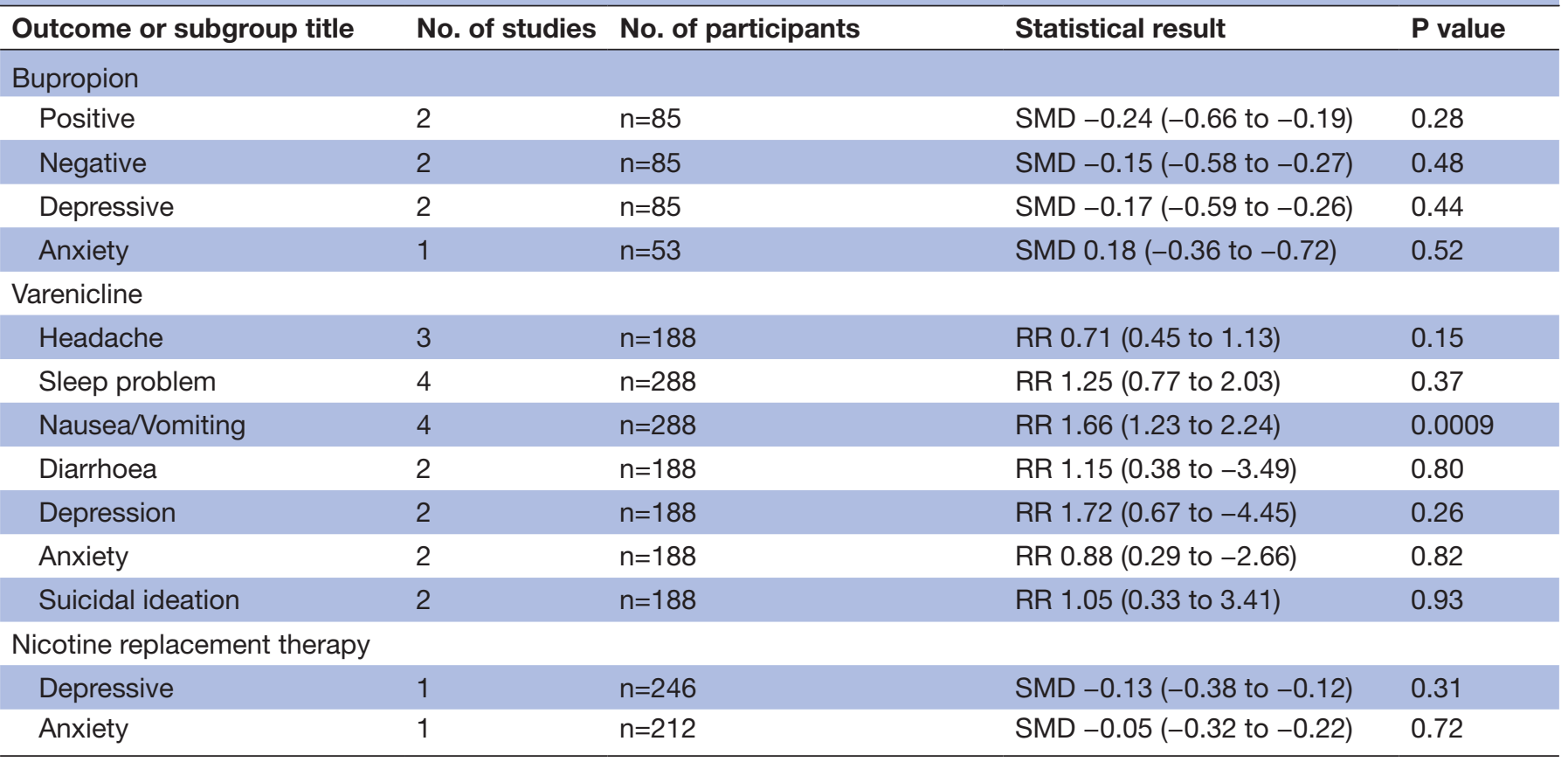

$\mathrm{RR}$, risk ratio; $\mathrm{SMD}$, standardised mean difference.

people with serious mental illness, with outcomes at 3, 6 and 12 months. The primary new information of this review was the effectiveness of varenicline at 3 and 6 months but the lack of evidence to support the use of bupropion and nicotine products to achieve smoking cessation for $>3$ months. We also found that these treatments did not notably affect the physical or mental health of the participants, with generally low levels of side effects. Varenicline was the most successful treatment with individuals more

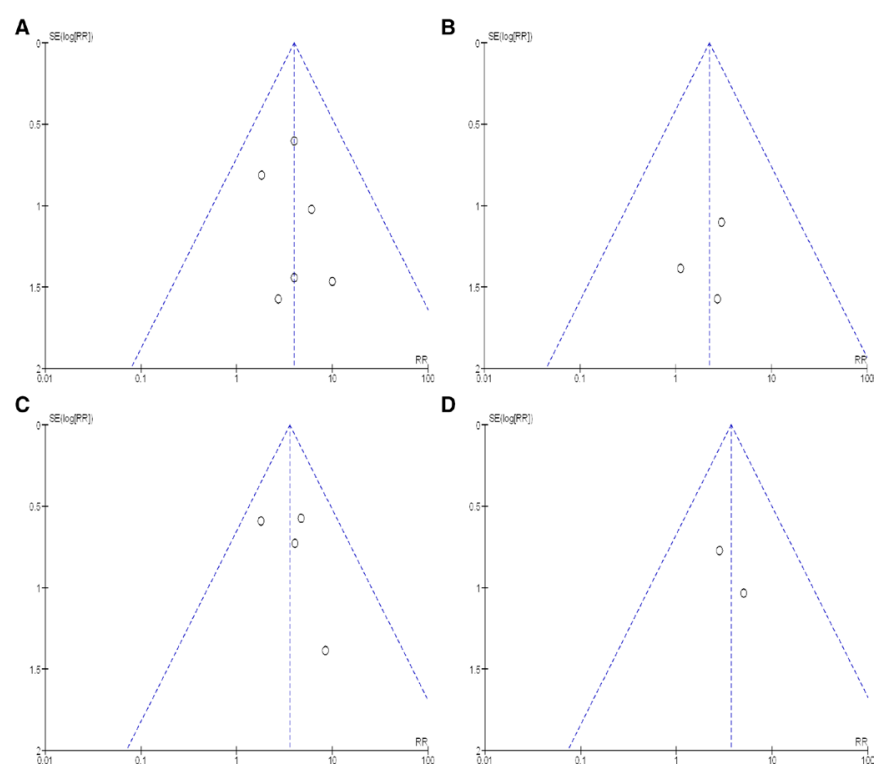

Figure 8 Funnel plots of smoking cessation studies. (A) Funnel plot of comparison: bupropion 3 months. (B) Funnel plot of comparison: bupropion 6 months. (C) Funnel plot of comparison: varenicline 3 months. (D) Funnel plot of comparison: varenicline 6 months. $\mathrm{RR}$, risk ratio. than three times as likely to achieve smoking cessation in both schizophrenia and bipolar disorders. Problems with side effects from nausea and vomiting were found with varenicline. Bupropion increased the cessation of smoking in the short term (up to 3 months) compared with placebo, at a dose of $300 \mathrm{mg}$ /day, but there was a lack of evidence to support its use in achieving sustained cessation of smoking over a longer period. Only one small study was found that used NRT and this was only effective for a period of up 3 months. We found that combining bupropion and NRT was only effective at 3 months. However, when all studies of bupropion were pooled at 6 months, both single treatments using bupropion and those using concurrent bupropion and nicotine, stronger evidence was observed. Behavioural interventions on the whole showed little benefit to achieve smoking cessation. Counselling and behavioural or specialised bespoke programmes used different types of interventions to achieve smoking cessation but no consistent effect was found. Contingency reinforcement combined with NRT was found to be beneficial for achieving smoking cessation compared with contingency reinforcement alone. Comparison of the effect of behavioural or contingency programmes versus pharmacological interventions could not be made due to the heterogeneity of the active and comparison groups used.

There are strengths and limitations to the findings we have presented. We found that effective methods are available to increase rates of smoking cessation both in schizophrenia and bipolar affective disorder. However, this evidence is based on relatively few studies. We identified all randomised trials including results available at both 3 and 6 months, and identified studies that used 


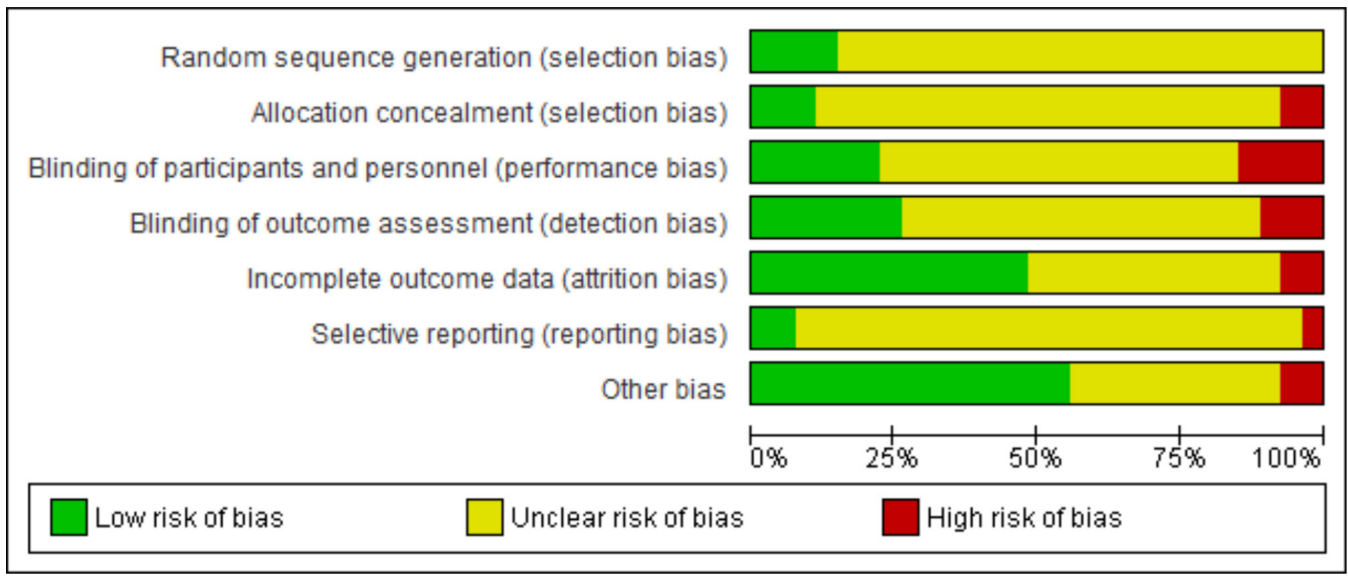

Figure 9 Risk of bias graph: review authors' judgements about each risk of bias item presented as percentages across all included studies.

chemical markers to confirm smoking abstinence. A number of limitations however need to be acknowledged. Research in this field has been so far limited by only a small number and low quality of randomised controlled trials. For example, some of the conclusions from this review are based on a single study of NRT. It is possible that additional studies with negative outcomes have been conducted but remain unpublished. We found generally low levels of side effects with both bupropion use and varenicline. However, we are aware that studies comprising larger samples are still required to fully resolve issues of whether there are a greater potential risk of suicidality and other neuropsychiatric effects with these products used for smoking cessation.

Our findings update and review the latest evidence in this field and show that successful treatment for smoking dependence is available in people with serious mental illness. However, our conclusions differ in respect of the final analysis of treatments using bupropion therapy. For example, Tsoi et $a t^{41}$ in a Cochrane systematic review of patients with schizophrenia (last search November 2012) found that bupropion was effective at both 3 and 6 months. Their final conclusions differed from our own in their summary of findings of bupropion reported at 6 months. Their final analysis of bupropion studies at 6 months incorporated both studies where bupropion was used singly as the primary treatment offered and also those using concurrent treatments of bupropion and nicotine therapy. The pooled effect of the larger sample size found stronger evidence to support the use of bupropion at 6 months treatment. A recent systematic review by Peckham et $a l^{42}$ similarly incorporated into their findings of bupropion studies that jointly used bupropion and NRT. In our review, we have reported the outcomes of bupropion separately as, first, we did not think it likely that clinicians would incorporate two concurrent treatments for smoking cessation, and second, existing meta-analysis of studies in the general population have tended to compare one product for smoking cessation solely with another. ${ }^{43}$
The results of our review are tempered by the relatively low numbers of randomised trials in this field, most trials being underpowered, and the poor quality of evidence identified by the GRADE assessment. For example, only two studies showed the effectiveness of varenicline at 6 months, and only one study ${ }^{44}$ was found examining nicotine products, compared with up to 70 studies comparing NRT in the general population. We found low levels of side effects, with varenicline mainly causing symptoms of nausea and vomiting. We are aware that a larger study has been recently completed ${ }^{45}$ examining the neuropsychiatric effects of varenicline, bupropion and NRT in individuals with or without psychiatric disorders $(n=4074)$, comprising unipolar and bipolar disorders, anxiety disorders, personality disorders and psychotic illness. This study did not find a greater risk of neuropsychiatric side effects associated with these medications. Data were not available (authors contacted) for inclusion in this review and meta-analysis.

\section{Implications for practice}

This is a new and updated systematic review directly comparing treatments to aid cessation of smoking in people with schizophrenia and bipolar affective disorders. We found that smoking cessation was more likely to be successful using varenicline in both schizophrenia and bipolar disorders with few side effects but there was a lack of sufficient evidence to support the use of bupropion as a single treatment in the medium and long term. Treatment with varenicline resulted in $24.8 \%$ of the patients at 3 months in the varenicline group vs $7.3 \%$ in the placebo group being abstinent from smoking (at 6 months, $13.8 \%$ vs $4.2 \%$, respectively). However, our review is notable by the low number of studies available for each smoking cessation treatment.

\section{Implications for research}

Further research is needed to conduct well-designed studies of adequate sample size to determine the most effective method for reducing smoking in this population. 
Studies so far have also achieved only relatively shortterm effects on sustained smoking abstinence. Tailored or focused programmes may be needed using single or combinations of treatments to achieve better outcomes. Similarly, clearer evidence is required to understand which type of counselling or psychological intervention is the most effective. Furthermore, existing smoking cessation programmes tend to rely on evidence from general population samples. It is not clear whether these are transferable to people with serious mental illnesses with substantially higher levels of smoking and nicotine dependence. However, we also need to be realistic as to the problems of change in this population who as a result of the nature of their mental illness may be less motivated or less able to change their lifestyle. ${ }^{4647}$

\section{CONCLUSIONS}

This review highlighted the paucity of studies found to address the high prevalence of smoking in people with SMI and identifies a need for further randomised controlled trials. The available evidence suggested that varenicline was the most effective with low levels of side effects, but there was a lack of sufficient evidence to support the use of bupropion and NRT within this group.

Contributors RP, DJS and JRG developed the research. RP conducted the research. RP and DJS conducted the analysis. RP drafted the manuscript. DJS and JRG provided input and approved the final version.

Funding The authors have not declared a specific grant for this research from any funding agency in the public, commercial or not-for-profit sectors.

Competing interests RP and DJS declared no competing interests. JG has received research funding from MRC, ESRC, NIHR, Stanley Medical Research Institute and has received donations of drugs supplies for trials from Sanofi-Aventis and GSK. He has acted as an expert witness for Dr Reddys.

Patient consent for publication Not required.

Provenance and peer review Not commissioned; externally peer reviewed.

Data sharing statement № other unpublished data are available for this study.

Open access This is an open access article distributed in accordance with the Creative Commons Attribution Non Commercial (CC BY-NC 4.0) license, which permits others to distribute, remix, adapt, build upon this work non-commercially, and license their derivative works on different terms, provided the original work is properly cited, appropriate credit is given, any changes made indicated, and the use is non-commercial. See: http://creativecommons.org/licenses/by-nc/4.0/.

ORCID iD

Daniel J Smith http://orcid.org/0000-0002-2267-1951

\section{REFERENCES}

1 Goff DC, Sullivan LM, McEvoy JP, et al. A comparison of ten-year cardiac risk estimates in schizophrenia patients from the CATIE study and matched controls. Schizophr Res 2005;80:45-53.

2 McCreadie RG. Scottish Schizophrenia Lifestyle Group. Diet, smoking and cardiovascular risk in people with schizophrenia: descriptive study. Br J Psychiatry 2003;183:534-9.

3 Susce MT, Villanueva N, Diaz FJ, et al. Obesity and associated complications in patients with severe mental illnesses: a crosssectional survey. J Clin Psychiatry 2005;66:167-73.

4 Scottish Health Survey 2. The Scottish Government, Edinburgh, 2010. www. scotland.gov.uk/publications.

5 Kelly DL, McMahon RP, Wehring HJ, et al. Cigarette smoking and mortality risk in people with schizophrenia. Schizophr Bull 2011;37:832-8.
6 Saha S, Chant D, McGrath J. A systematic review of mortality in schizophrenia: is the differential mortality gap worsening over time? Arch Gen Psychiatry 2007;64:1123-31.

7 Leucht S, Burkard T, Henderson J, et al. Physical illness and schizophrenia: a review of the literature. Acta Psychiatr Scand 2007;116:317-33.

8 de Leon J, Diaz FJ. A meta-analysis of worldwide studies demonstrates an association between schizophrenia and tobacco smoking behaviors. Schizophr Res 2005;76:135-57.

9 Kelly C, McCreadie RG. Smoking habits, current symptoms, and premorbid characteristics of schizophrenic patients in Nithsdale, Scotland. Am J Psychiatry 1999;156:1751-7.

10 Lohr JB, Flynn K. Smoking and schizophrenia. Schizophr Res 1992;8:93-102.

11 Williams JM, Ziedonis DM, Abanyie F, et al. Increased nicotine and cotinine levels in smokers with schizophrenia and schizoaffective disorder is not a metabolic effect. Schizophr Res 2005;79:323-35.

12 Strand JE, Nybäck H. Tobacco use in schizophrenia: a study of cotinine concentrations in the saliva of patients and controls. Eur Psychiatry 2005:20:50-4.

13 Hall SM, Prochaska JJ. Treatment of smokers with co-occurring disorders: emphasis on integration in mental health and addiction treatment settings. Annu Rev Clin Psychol 2009;5:409-31.

14 Cerimele JM, Durango A. Does varenicline worsen psychiatric symptoms in patients with schizophrenia or schizoaffective disorder? J Clin Psychiatry 2012;73:e1039-e1047.

15 US Food and Drug Administration. FDA Alert. Information for Healthcare Professionals: Varenicline (marketed as Chantix) and Bupropion (marketed as Zyban, Wellbutrin, and generics). 2009. US Food and Drug Administration http://www.fda.gov/downloads/ AdvisoryCommittees/ CommitteesMeetingMaterials/Drugs/

16 Dickersin K, Scherer R, Lefebvre C. Identifying relevant studies for systematic reviews. Br Med J 1994;309:1286.

17 Moher D, Liberati A, Tetzlaff J, et al. Preferred reporting items for systematic reviews and meta-analyses: the PRISMA statement. PLoS Med 2009;6:e1000097.

18 Mantel N, Haenszel W. Statistical aspects of the analysis of data from retrospective studies of disease. J Natl Cancer Inst 1959;22:719-48.

19 Higgins JPT, Green S. Cochrane handbook for systematic reviews of interventions. England: Wiley-Blackwell, 2008.

20 Egger M, Smith GD, Altman DG. Systematic reviews in health care meta-analysis in context 2e: John Wiley \& Sons.

21 Weinberger AH, Vessicchio JC, Sacco KA, et al. A preliminary study of sustained-release bupropion for smoking cessation in bipolar disorder. J Clin Psychopharmacol 2008;28:584-7.

22 Wu BS, Weinberger AH, Mancuso E, et al. A preliminary feasibility study of varenicline for smoking cessation in bipolar disorder. J Dual Diagn 2012;8:131-2.

23 Chengappa KN, Perkins KA, Brar JS, et al. Varenicline for smoking cessation in bipolar disorder: a randomized, double-blind, placebocontrolled study. J Clin Psychiatry 2014;75:765-72.

24 Bennett ME, Brown CH, Li L, et al. Smoking cessation in individuals with serious mental illness: a randomized controlled trial of two psychosocial interventions. J Dual Diagn 2015;11:161-73.

25 Gilbody S, Peckham E, Man MS, et al. Bespoke smoking cessation for people with severe mental ill health (SCIMITAR): a pilot randomised controlled trial. Lancet Psychiatry 2015;2:395-402.

26 Baker A, Richmond $\mathrm{R}$, Haile $\mathrm{M}$, et al. A randomized controlled trial of a smoking cessation intervention among people with a psychotic disorder. Am J Psychiatry 2006;163:1934-42.

27 Chen HK, Lan TH, Wu BJ. A double-blind randomized clinical trial of different doses of transdermal nicotine patch for smoking reduction and cessation in long-term hospitalized schizophrenic patients. Eur Arch Psychiatry Clin Neurosci 2013;263:75-82.

28 George TP, Vessicchio JC, Sacco KA, et al. A placebo-controlled tria of bupropion combined with nicotine patch for smoking cessation in schizophrenia. Biol Psychiatry 2008;63:1092-6.

29 Evins AE, Cather C, Culhane MA, et al. A 12-week double-blind, placebo-controlled study of bupropion sr added to high-dose dual nicotine replacement therapy for smoking cessation or reduction in schizophrenia. J Clin Psychopharmacol 2007;27:380-6.

30 Williams JM, Steinberg ML, Zimmermann MH, et al. Comparison of two intensities of tobacco dependence counseling in schizophrenia and schizoaffective disorder. J Subst Abuse Treat 2010;38:384-93.

31 George TP, Ziedonis DM, Feingold A, et al. Nicotine transdermal patch and atypical antipsychotic medications for smoking cessation in schizophrenia. Am J Psychiatry 2000:157:1835-42.

32 Evins AE, Cather C, Deckersbach T, et al. A double-blind placebo-controlled trial of bupropion sustained-release for smoking cessation in schizophrenia. J Clin Psychopharmacol 2005;25:218-25. 
33 Weiner E, Ball MP, Buchholz AS, et al. Bupropion sustained release added to group support for smoking cessation in schizophrenia: a new randomized trial and a meta-analysis. J Clin Psychiatry 2012;73:95-102.

34 Williams JM, Gandhi KK, Lu SE, et al. Nicotine intake and smoking topography in smokers with bipolar disorder. Bipolar Disord 2012;14:618-27.

35 Williams JM, Anthenelli RM, Morris CD, et al. A randomized, doubleblind, placebo-controlled study evaluating the safety and efficacy of varenicline for smoking cessation in patients with schizophrenia or schizoaffective disorder. J Clin Psychiatry 2012;73:654-60.

36 Gallagher SM, Penn PE, Schindler E, et al. A comparison of smoking cessation treatments for persons with schizophrenia and other serious mental illnesses. J Psychoactive Drugs 2007;39:487-97.

37 George TP, Vessicchio JC, Termine A, et al. A placebo controlled tria of bupropion for smoking cessation in schizophrenia. Biol Psychiatry 2002:52:53-61.

38 Tidey JW, Rohsenow DJ, Kaplan GB, et al. Effects of contingency management and bupropion on cigarette smoking in smokers with schizophrenia. Psychopharmacology 2011;217:279-87.

39 Wing VC, Bacher I, Daskalakis ZJ, et al. A preliminary study of repetitive transcranial magnetic stimulation for smoking cessation in schizophrenia. Neuropsychopharmacology 2010;35:S163.

40 Smith RC, Amiaz R, Si TM, et al. Varenicline effects on smoking, cognition, and psychiatric symptoms in schizophrenia: a doubleblind randomized trial. PLoS One 2016;11:e0143490.

41 Tsoi DT, Porwal M, Webster AC. Interventions for smoking cessation and reduction in individuals with schizophrenia. Cochrane Database Syst Rev 2013:CD007253.

42 Peckham E, Brabyn S, Cook L, et al. Smoking cessation in severe mental ill health: what works? an updated systematic review and meta-analysis. BMC Psychiatry 2017;17:252.

43 Cahill K, Stevens S, Perera R, et al. Pharmacological interventions for smoking cessation: an overview and network meta-analysis. Cochrane Database Syst Rev 2013;5:CD009329.

44 Wu P, Wilson K, Dimoulas P, et al. Effectiveness of smoking cessation therapies: a systematic review and meta-analysis. BMC Public Health 2006;6:300.

45 Anthenelli RM, Benowitz NL, West R, et al. Neuropsychiatric safety and efficacy of varenicline, bupropion, and nicotine patch in smokers with and without psychiatric disorders (EAGLES): a double-blind, randomised, placebo-controlled clinical trial. Lancet 2016;387:2507-20.
46 Muir-Cochrane E. Medical co-morbidity risk factors and barriers to care for people with schizophrenia. J Psychiatr Ment Health Nurs 2006;13:447-52.

47 Pearsall R, Hughes S, Geddes J, et al. Understanding the problems developing a healthy living programme in patients with serious mental illness: a qualitative study. BMC Psychiatry 2014;14:38.

48 Evins AE, Mays VK, Rigotti NA, et al. A pilot trial of bupropion added to cognitive behavioral therapy for smoking cessation in schizophrenia. Nicotine \& Tobacco Research 2001;3:397-403.

49 George TP, Vessicchio JC, Termine A, et al. A placebo controlled tria of bupropion for smoking cessation in schizophrenia. Biol Psychiatry 2002:52:53-61.

$50 \mathrm{Li} \mathrm{J}$, Zhang T, Wang B, et al. An efficacy analysis of bupropion for smoking cessation in schizophrenia. Zhongquo Xinyao yu Linchuang Zazhi 2009;28:231-4.

51 Akbarpour F, Rezaei O, Khodaie-Ardakani M-, et al. A doubleblind placebo-controlled trial of bupropion for smoking abstinence and cognition improvement in schizophrenia. Minerva Psichiatr 2010;51:263-9.

52 Bloch B, Reshef A, Cohen T, et al. Preliminary effects of bupropion and the promoter region (HTTLPR) serotonin transporter (SLC6A4) polymorphism on smoking behavior in schizophrenia. Psychiatry Res 2010;175:38-42.

53 Weiner E, Buchholz A, Coffay A, et al. Varenicline for smoking cessation in people with schizophrenia: a double blind randomized pilot study. Schizophr Res 2011;129:94-5.

54 Shim J-, Jung D, Oh M, et al. Varenicline treatment for smoking cessation in people with schizophrenia: A randomized double-blind placebo-controlled trial. Schizophr Bull 2011;37:320-1.

55 Hong $\mathrm{E}$. Moderate dose varenicline treatment on neurobiological and cognitive biomarkers in schizophrenia smokers and non-smokers. Neuropsychopharmacology 2011;36:S97-S98.

56 George TP, Ziedonis DM, Feingold A, et al. Nicotine transdermal patch and atypical antipsychotic medications for smoking cessation in schizophrenia. Am J Psychiatry 2000;157:1835-42.

57 Weinberger AH, George TP, Perkins KA, et al. Effects of topiramate on smoking in patients with schizoaffective disorder, bipolar type. $J$ Clin Psychopharmacol 2008;28:247-8.

58 Szombathyne-Meszaros Z, Dimmock JA, Ploutz-Snyder R, et al. Oral naltrexone treatment for alcohol dependence in schizophrenia is not effective for smoking cessation. Alcoholism: Clinical and Experimental Research 2010;34:176A. 